DOI : https://doi.org/10.3126/njmr.v2i3.26976

\title{
Economic Impact on Oral Health Care Practices of Rural People of Lalitpur District, Nepal
}

\author{
Amit Kumar Sakha, PhD Scholar (MUR1403028), Mewar University, Chittorgarh, Rajasthan, \\ India \\ Prof. Dr. Uma Kant Silwal, Research Co-Supervisor, Mewar University, Chittorgarh, \\ Rajasthan, India
}

\section{Correspondent}

Amit Kumar Shakha

amitkshakha@gmail.com

\begin{abstract}
People should be conscious for the proper caring of health and immediate response on health problem because creative mind is the output of sound health. Oral health problem is also sensitive issue so it should be cared properly with timely treatment. The main objective of this study is to identify the economic impact on oral health practices of rural people of Lalitpur district of Nepal. The study was conducted among the 369 oral health patients and discussed about their economic status and its impact on their health seeking practices. The result found that there was no significant impact of economic status on their oral health practices. Sociocultural and other environmental factors may be responsible to determines the oral health practices so future researchers can study on the role of other socio-cultural factors on oral health practices.
\end{abstract}

Keywords: Economic, Health care, Impact, Practices, Rural

\section{Introduction}

Health care is the primary concern of people. The primary function of health systems is to provide high-quality and universal health services (Boyce \& Brown, 2019). The expansion of quality health service is the main priority of Nepal government also. Nepal moved from unitary system with a three-level federal system of government. A key concern associated with implementing federalism is the de-prioritization of the social sector, including health, over other needs. The major challenge during the transition phase is to ensure that there are uninterrupted supplies of medical commodities and services in community level health services. This requires scaling up the ability of local bodies to manage drug procurement and general logistics and adequate human resource in local healthcare centres (Thapa, Bam, Tiwari, Sinha, \& Dahal, 2019). Nepal government has to develop the infrastructure facilities, capacity of local bodies, effective mobilization of human resources for the betterment of health facilities in rural societies. 
From the socio-economic perspective, there are various causative factors associated with the effective use of health services by rural people. The poverty, illiteracy, accessibility, awareness, cultural practices and other environmental factors are responsible to determines the health seeking behaviour of rural people. Among the various factors, poverty is the major causative factor which directly effect in health treatment and inadequate access on better health facilities.

Nepal is a low-income country with a per capita gross domestic product of $\$ 21.13$ billion and a gross national income per capita of $\$ 730$ as of 2016 (World Bank Group , 2016). The household expenditure on health care is only about $5.5 \%$ of the total household expenditure (Hotchkiss, Rous, Karmacharya, \& Sangraula, 1998). In addition to limited financial resources, illiteracy and belief in traditional healing techniques among Nepalese may further limit their health-seeking behavior (Sanjel, Mudbhari, Risal, \& Khanal, 2012; Gurung, Paudel, \& Yadav, 2016). The literacy rate of Nepal is 65.9\% (male: 75.1\%; female: 57.4\%) (Central Bureau of Statistics, 2012). More than half of Nepali women visited traditional healers for health care, and irrespective of age, gender or ethnicity, faith healers are the first choice of treatment (Adhikari \& Rijal, 2014; Shrestha, Paudel, Pant, Neupane, \& Manandhar, 2017).

Nepal aims to accelerate universal health coverage (UHC). The National Health Policy of Nepal (2014) aims to improve access to quality and equitable health services and provide basic healthcare services (BHCS) free of charge while non BHCS will be covered through the social health insurance (Ministry of Health, 2014). This aim is reflected in strategic papers, including the Nepal Health Sector Strategy 2015-2020 (Ministry of Health and Population, 2015) which outlines four strategic directions: health system reform, equitable access, improved quality of services, and multi-sectoral approaches. The high out of pocket expenditure is a major barrier to health service use for many Nepali people. Approximately $10.7 \%$ of the population have experienced catastrophic financial exposures, with $1.67 \%$ of the population falling below the poverty line because of health expenditures (World Health Organization, 2017). The health expenditure is gradually increasing in Nepal which is beyond the capacity of poor people. Many private hospitals are establishing with exaggerated advertisement of best treatment which charges high cost with patients. In this context, economic aspect might be the barrier of health services. So, the study become interested to identify the economic impact on oral health care practices of rural people of Nepal.

\section{Materials \& Methods}

The study was conducted in rural society of Lalitpur district among the 369 oral health patients. It is based on cross-sectional design. The respondents were selected purposively having with some criteria of oral health problem. It is quantitative study so data was collected by using the structured questionnaire survey. Researcher had taken the written consent of all respondents and ensured the confidentiality of given information. The statistical analysis was done to identify the relationship between the monthly income and oral health practices. 


\section{Results \& Discussions}

The study had discussed on the economic status of oral health patients and their health seeking behavior. There are various factors which effect on the health seeking behaviours of people but among them economic status or income is one of the most important factor. There is strong relationship between the economic status and health treatment practices of community people. The study had analyzed relationship between the monthly income and oral health treatment, experience of visiting traditional healers, visiting to dentist and changing a toot-brush.

\section{Types of health facility for oral health check up}

The data presented in Table 1 shows that higher number (66.1\%) patient visited the private clinic for the checkup of oral health problem whereas only $22.8 \%$ visited to government hospital. The data indicates that the oral health checkup was affordable for the majority of community people. On the other hand, due to very crowd in government hospital and delay in all process of treatment like getting appointment of Doctor, long waiting time in OPD, no proper sitting arrangement in doctor waiting room, delay due to crowd of patient in diagnosis and lab test. The respondents shared that there was no good caring of patients and patients or patients party could not get adequate time of doctor to discuss about the nature of diseases. Weak counselling from the health personal was reported on cause that very little number of patient visited to government hospital in comparison of private hospital and clinic.

Table 1: Types of health facility for oral health check up

\begin{tabular}{|c|c|c|c|c|}
\hline & & Monthly incor & & Total \\
\hline & Less than 10000 & $10000-20000$ & More than 20000 & \\
\hline Government hospital & $25.5 \%$ & $22.2 \%$ & $17.5 \%$ & $22.8 \%$ \\
\hline Private clinic & $59.4 \%$ & $72.2 \%$ & $67.5 \%$ & $66.1 \%$ \\
\hline Local health center & $3.8 \%$ & $5.6 \%$ & $5.0 \%$ & $4.7 \%$ \\
\hline No where & $11.3 \%$ & $0.0 \%$ & $10.0 \%$ & $6.3 \%$ \\
\hline Total & $100.0 \%$ & $100.0 \%$ & $100.0 \%$ & $100.0 \%$ \\
\hline
\end{tabular}

Source: Field Survey, 2019

The table shows the relationship between income level and practice of visiting the types of health center. The data shows that more (72.2\%) middle income group (10000-20000) people had visited private clinic than other income group. the second largest groups (67.5\%) from those groups who were earning more than 20000 monthly income visited the private clinic for oral health check-up.

\section{Experience to visit Traditional Healer (Dhami) during teeth pain}

It is the traditional practices of rural society of Nepal that still people believed on the traditional healer for the treatment of health problem. People used to visit traditional healer for the advice and treatment of health problem. It is also stated in the previous literature that traditional healing practices in rural Nepal has emerged together with its culture and tradition. In the rural areas traditional culture is still predominant and western allopathic medicine has yet to reach those areas. People of rural societies are reluctant to accept changes in their cultural practices. There 
are also a lot of factors that make people choose traditional healers in lieu of modern hospital/heath post services. However, modern health services are slowly replacing traditional healing practices in rural parts of Nepal (Baniya, 2014). As the finding of above literature, the study also found that the number of people visited to traditional healers was only $37.2 \%$ for the treatment of oral health problem whereas $62.8 \%$ not visited traditional healer.

Table 2: Experience to visit Traditional Healer (Dhami) during teeth pain

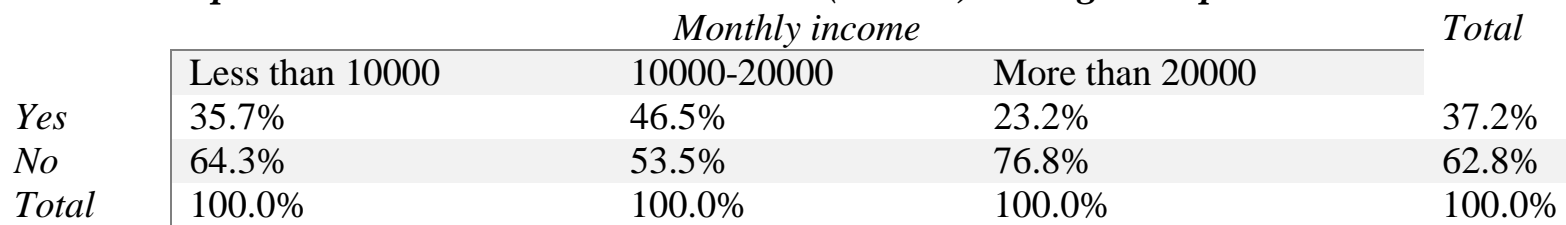

Source: Field Survey, 2019

The practice of visiting traditional healers at the time of oral health problem was analyzed from the economic status of respondents. The data shows that comparatively higher number $(46.5 \%)$ of middle monthly income group (10000-20000) visited to traditional healers followed by $35.7 \%$ from the less than 10000 monthly incomes and 23.2\% from who were earning more than 20000 monthly. Level of income is one determinant of practice of using the health service. Treatment of traditional healer is easier and less expensive than the treatment of hospital or clinic so it may be the reason that people visit to traditional healers. In the present context, health service is more expensive so it becomes the unaffordable for the poor people also.

Traditional medicines and healing systems are widely practiced in every community of Nepal. Large numbers of traditional healers are still actively continuing their indigenous and traditional medical knowledge and practices as a family tradition and culture. Traditional healers used more than 200 medicinal plants, minerals, sea, and animal products for treating more than 300 diseases (Aryal, et al., 2016). Such practices are still continuing in rural society due to domination of cultural belief system and low economic status of rural people to visit the hospital and health post.

\section{Correlation between Income and number of visit to oral health clinic in last 12 months}

The study had asked the patients about the number of visit to oral health clinic in last 12 months for the check up and treatment. The data presented in the Table 3 shows that there was no significant correlation between the monthly income of patients and number of visit to oral health clinic in last 12 months because the p value was .089 which is higher than .05 significant level.

Table 3: Correlation between Income and number of visit to oral health clinic in last 12 months

\begin{tabular}{|l|l|l|}
\hline \multicolumn{2}{|c|}{ Correlations } \\
\hline Monthly Income & $\begin{array}{l}\text { Number of visit to oral health clinic in last } \\
12 \text { months }\end{array}$ \\
\hline
\end{tabular}




\begin{tabular}{|l|l|l|l|}
\hline Monthly & Pearson Correlation & 1 & .089 \\
\cline { 2 - 4 } Income & Sig. (2-tailed) & & .089 \\
\cline { 2 - 4 } & $\mathrm{N}$ & 369 & 369 \\
\hline
\end{tabular}

Source: Field Survey, 2019

The result indicates that there was no effect of monthly income on frequency of visit to health center for the health checkup. The data has shown that even low income people had also visited the private clinic for the oral health checkup so the level of awareness and attitude towards the health may be determinants of their heath behavior. Attitude is the psychological phenomenon, is a tendency to respond positively or negatively towards a certain idea, object, person, or situation. Attitude is the affecting factor on the behavior of people and personality development (Karki, 2018). The attitude guides the action of people.

\section{Correlation between Income and changing period of tooth brush}

The study had also measured the correlation between the income level and changing period of tooth brush. The statistical result presented in Table 4 shows that there was no significant correlation between the monthly income and changing period of tooth brush because the $\mathrm{p}$ value was .438 which is higher than .05 significant level.

Table 4: Correlation between Income and changing period of tooth brush

\section{Correlations}

\begin{tabular}{|l|l|l|l|}
\hline \multicolumn{2}{|c|}{} & Monthly Income & $\begin{array}{l}\text { Changing period of tooth } \\
\text { brush }\end{array}$ \\
\hline \multirow{3}{*}{ Monthly Income } & Pearson Correlation & 1 & -.041 \\
\cline { 2 - 4 } & Sig. (2-tailed) & & .438 \\
\cline { 2 - 4 } & $\mathrm{N}$ & 369 & 369 \\
\hline
\end{tabular}

Source: Field Survey, 2019

The result indicates that there was no effect of monthly income in changing period of tooth brush. There were similar types of practices of changing period of tooth brush among the different income group. the changing period of tooth brush is more related with the knowledge of oral health. So it indicates that there might have effect of knowledge of oral health in their brush using practice.

\section{Conclusion}

In general, it is found from the study that there was no significant impact of economic status of people on their oral health care practices because majority of people had visited private clinic for their oral health checkup as well as higher number of patient visited doctor/clinic for treatment than the traditional healers. The statistical result clearly shows that there was no relation between monthly income of patient and frequency of visit to oral health clinic and changing of toothbrush. The knowledge and attitude and other environmental factors may be determinants for 
the health seeking behaviours of rural people. So future researchers can study on the role of other socio-cultural factors on oral health practices.

\section{References}

Adhikari, D., \& Rijal, D. (2014). Factors affecting health seeking behavior of senior citizens of Dharan. J Nobel Med Coll, 3, 50-57. doi:10.3126/jonmc.v3i1.10055

Aryal, K., Dhimal, M., Pandey, A., Pandey, A., Dhungana, R., Khaniya, B., . . Karki, K. (2016). Knowledge Diversity and Healing Practices of Traditional Medicine in Nepal. Kathmandu, Nepal: Nepal Health Research Council (NHRC).

Baniya, R. (2014, June). Traditional Healing Practices in Rural Nepal. Journal of Patan Academy of Health Sciences, 1(1), 52-53. doi:https://doi.org/10.3126/jpahs.v1i1.13020

Boyce, T., \& Brown, C. (2019). Economic and Social Impacts and Benefits of Health Systems. Denmark: WHO Regional Office for Europe.

Central Bureau of Statistics. (2012). National Population and Housing Census 2011. Kathmandu: Government of Nepal, National Planning Commission Secretariat.

Gurung, L., Paudel, G., \& Yadav, U. (2016). Health service utilization by elderly population in urban nepal: a cross-sectional study. J Manmohan Memor Inst Health Sci., 2, 27-36. doi:10.3126/jmmihs.v2i0.15794

Hotchkiss, D., Rous, J., Karmacharya, K., \& Sangraula, P. (1998). Household health expenditures in Nepal: implications for health care financing reform. Health Policy Plan, $13,371-383$.

Karki, T. B. (2018, December). Perceived Experience of Girls at the Time of Menstrual Period: A Study of School Student of Kathmandu, Nepal. Nepal Journal of Multidisciplinary Research (NJMR), 1(2), 9-16.

Ministry of Health. (2014). National Health Policy. Kathmandu, Nepal: Government of Nepal. Retrieved from http://nnfsp.gov.np/ PublicationFiles/a93626f6-5e96-4cf6-b96ec282addd4832.pdf

Ministry of Health and Population. ( 2015). Nepal Health Sector Strategy, 2015-2020. Kathmandu, Nepal: Saugat Printing and Publication . Retrieved from http://nhsp.org.np/nepal-healthsector-strategy-2015-2020/

Sanjel, S., Mudbhari, N., Risal, A., \& Khanal, K. (2012). The utilization of health care services and their determinants among the elderly population of Dhulikhel Municipality. Kathmandu Univ Med J. , 10, 24-29. doi:10.3126/kumj.v10i1.6911 
Shrestha, M., Paudel, L., Pant, S., Neupane, S., \& Manandhar, N. (2017). Health seeking behavior among women in Bhimtar, Sindhupalchowk district of Nepal. Int J Commun Med Public Health, 4, 1854-1857. doi:10.18203/2394-6040.ijcmph20172144

Thapa, R., Bam, K., Tiwari, P., Sinha, T., \& Dahal, S. (2019). Implementing federalism in the health system of Nepal: opportunities and challenges. Int J Health Policy Manag, 8(4), 195-198. doi:doi:10.15171/ijhpm.2018.121

World Bank Group . (2016). World Bank Data on Nepal . Nepal: World Bank Group . Retrieved from https://data.worldbank.org/country/Nepal

World Health Organization. (2017). Health financing profile 2017: Nepal. WHO, Regional Office for South-East Asia. Retrieved from http://www.who.int/iris/ handle/10665/259643 